\title{
Dental health of survivors of malignant disease
}

\author{
R R WELBURY, A W CRAFT, J J MURRAY, AND J KERNAHAN \\ Departments of Child Health and Child Dental Health, Royal Victoria Infirmary, Newcastle upon Tyne
}

SUMmary A full dental examination on 64 children aged from 3 to 20 years who were in long term remission from malignant disease showed normal facial growth, caries incidence, and periodontal indices. There was increased incidence of hypodontia and hypoplasia which in some could be ascribed to the original disease or its treatment.

There is an increasing awareness of the late effects of treatment in children surviving malignant disease. While acute oral manifestations in children who have cancer are well recognised, ${ }^{1}$ no follow up studies have been performed on those off treatment to determine what effects the treatment or the disease, or both, have had on the developing dentition.

\section{Patients and methods}

Sixty four children (37 with leukaemia and 27 with solid tumours) underwent a full clinical and radiographic dental examination. They were aged between 3 and 20 years and were off all treatment. None had suffered from a localised tumour of the head or neck and none had received radiotherapy to this region other than cranial irradiation in children with leukaemia. The gingival indices of $\mathrm{Loe}^{2}$ were used to assess gingival disease and oral hygiene. Caries was charted for all teeth, both permanent and deciduous. Erupted teeth were classified as any tooth where any part of the crown was visible in the mouth and where necessary an orthopantomogram was taken to assess unerupted teeth. Hypoplastic teeth, that is teeth with white patches, coloured flecks, or horizontal lines were noted. Gingival recession, tooth mobility, occlusion, and mouth opening were all recorded as was the presence of any soft tissue ulcer or other abnormality. Radiographs were taken when clinically indicated. Any abnormality found was correlated with the timing and history of the child's malignant disease treatment.

\section{Results}

No variation from normal was seen in dental caries, periodontal disease, occlusion, or mouth opening.
There was evidence of hypodontia, that is permanent teeth which had never erupted and were not present on radiographs, in $12(19 \%)$ children. The general population have been reported as having 3.5 to $6.5 \%$ of such teeth. ${ }^{3}$ Hypodontia could be possibly ascribed to the disease or chemotherapy in $8 \%$ of the children in the study by virtue of a knowledge of the time of development of tooth buds.

Twenty three $(36 \%)$ of the patients had hypo-

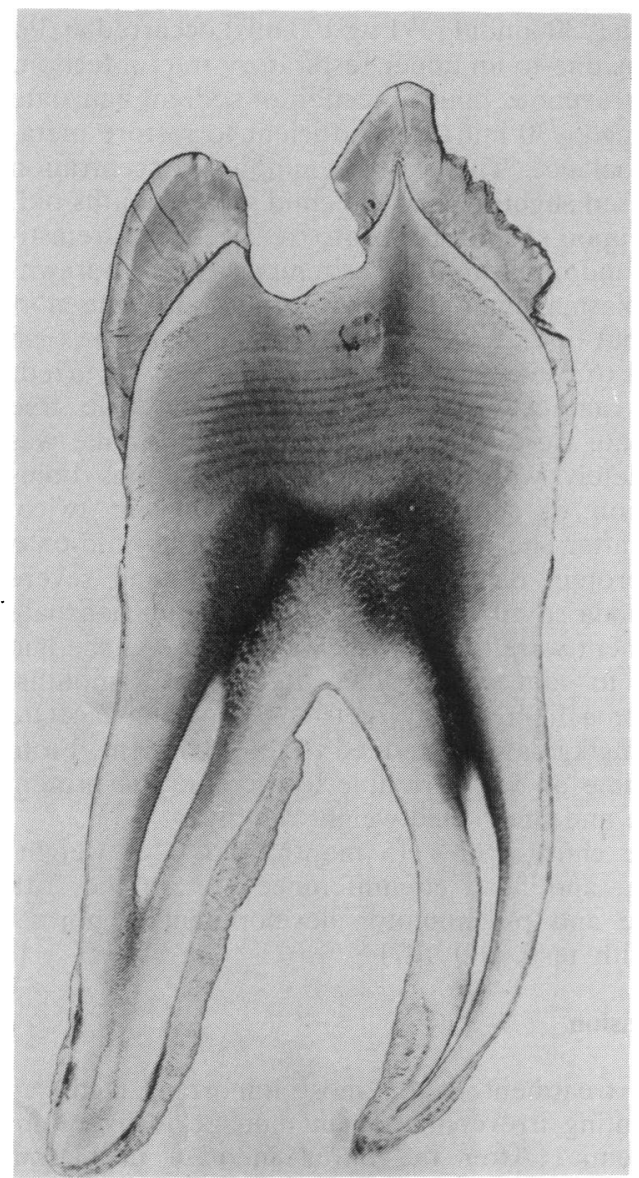

Figure A hollow ground section of an extracted upper first permanent pre-molar tooth showing prominent incremental lines in the crown dentine. 
plastic teeth, and of these half could possibly be associated with timing of treatment.

One permanent tooth has been extracted from a patient in the study and ground sections show prominent incremental lines in dentine and abnormal morphology of the root apex with early cessation of dentinogenesis (Figure). The timing of these abnormalities are in keeping with them having occurred during the treatment for the malignant disease.

There was no difference in the hypodontia and hypoplasia between the children who had had leukaemia or solid tumours.

\section{Discussion}

The effects of chemotherapeutic agents on the developing dentition have been extensively studied in animals, but only once in humans. ${ }^{4}$ No abnormalities were found in the soft tissues in the present study, and the degree of caries was no more than in the general population. No abnormality of occlusion or mouth opening was seen, although this might have been expected in children with leukaemia whose temporomandibular joint would have been close to the cranial radiotherapy field. The increased incidence of hypodontia and hypoplasia can only be explained in part by the effects of chemotherapy or the disease itself. Many of the abnormalities must have occurred at times outside of the treatment period. In animals there is a variable response of the teeth to chemotherapy, ${ }^{5}$ and it is likely that a similar variability would occur in man, so hypodontia and hypoplasia are not inevitable consequences of cancer chemotherapy. Indeed we have seen many completely normal teeth which must have developed during the period of cancer chemotherapy. The increased incidence of hypodontia may reflect delayed rather than absent tooth development, and only further follow up will elucidate this. In spite of these abnormalities and in view of the severe acute oral complications from which many children suffer during chemotherapy we were agreeably surprised at how healthy these children's teeth were.

\footnotetext{
References

1 Peterson D, Sonis S. Oral complications of cancer chemotherapy: present status and future studies. Cancer Treat Rep 1982;66:1251-6.

${ }^{2}$ Loe $\mathrm{H}$. The gingival index, the plaque index and the retention index systems. J Periodontol 1967;38:610-6.

${ }^{3}$ Brook A. Dental abnormalities of number, form and size: their prevalence in British schoolchildren. Journal of the International Association of Dentistry for Children 1974;5:37-53.

4 Adatia A. Response of the dental elements to chemotherapy of Burkitts tumour. Int Dent J 1968;18:646-53.

5 Vahlsing HL, Kim S-K. Feringa BR. Cyclophosphamide induced abnormalities in the incisors of the rat. $J$ Dent Res 1977;56:805-16.
}

Correspondence to Dr A W Craft, Children`s Department, Royal Victoria Infirmary, Newcastle upon Tyne, NE1 4LP.

Received 16 July 1984

\title{
Placental steroid sulphatase deficiency
}

\author{
A A ATTENBURROW, M HESLIP, M J HENDERSON, J B HOLTON, \\ I V SCOTT, AND L J H ARTHUR
}

Departments of Paediatrics and Obstetrics, Derby City Hospital and Department of Clinical Chemistry, Southmead General Hospital, Bristol

SUMMARY Low maternal plasma and urinary oestrogen concentrations in pregnancy are usually indicative of fetal problems, either placental insufficiency or fetal adrenal hypoplasia. Paediatricians, however, should follow obstetricians in becoming increasingly aware that deficiency of placental steroid sulphatase activity, a condition related to $\mathrm{X}$ linked ichthyosis, may produce the same abnormalities.
Obstetricians first became aware of placental steroid sulphatase deficiency in $1969 .{ }^{1}$ It is associated with low concentrations of maternal plasma and urinary oestrogens, raised values of steroid sulphates, but normal human placental lactogen concentrations, and results from the inability of the placenta to metabolise steroid sulphates. The differential diagnosis is placental insufficiency or fetal adrenal hypoplasia, both conditions with a worrying prognosis. There is an association with delayed onset of labour, poor progress during labour, and failure to 